\title{
Plasma Technology for Producing Coverings on Building Materials
}

\author{
Alexey Lykov ${ }^{1}$ and Nataliya Mokrova ${ }^{2, *}$ \\ ${ }^{1}$ Head of Department, State University of Land Use Planning, Russia, Moscow, 105064, 15, \\ Kazakova Str. \\ ${ }^{2}$ Moscow State University of Civil Engineering, Yaroslavskoe shosse, 26, Moscow, 129337, Russia
}

\begin{abstract}
Results of plasma processing of construction materials are presented in the article. The article also covers the plasma generator construction and technology of receiving protectively decorative covering on concrete that were developed by the authors. This plasma generator construction and technology provide coverings on concrete with strength and production characteristics that are superior to the existing alternatives. Results of the calculation and experimental research of the surface layer are presented. The technological parameters that influence the characteristics of the covering are given.
\end{abstract}

\section{Introduction}

The creation of various special coverings (waterproof, anti-corrosion, protective and decorative) on construction materials allows improving their operating characteristic and architectural expressiveness.

One of the methods of obtaining such coverings is plasma technology.

Such coverings are used in various industries, for example, in the construction industry to produce protective and decorative coverings, in the chemical industry it is used to receive the anticorrosive coverings on materials for lining devices of chemical industries, in the nuclear industry on materials used in the disposal of radioactive waste, etc.

\section{Plasma technology of receiving protective and decorative coverings}

Plasma technology is based on the creation of the molten layer on the surface of the material or on surfacing additional material on the surface of a building product made of concrete, brick or other building materials.

The results received during the creation of protective and decorative coverings on concrete by melting the surface are presented in this work.

*Corresponding author: natali_vm@ mail.ru 
To obtain protective and decorative coverings with high operational characteristics it is necessary to carry out rapid heating and melting of the material surface.

Protective and decorative coverings can be obtained by melting the surface with a plasma jet flowing from a high-frequency plasma generator [1]. Low heat flux in the material leads to overheating of the treatment surface. This affects strength and performance of the covering. High-intensity heating of the surface reduces the degree of the crystal hydrate destruction of the cement stone in the transition layer (the molten layer is the main material). The plasma generator with the electric arc controlled by magnetic fields satisfies the technological requirements [2]. The scanning of the electric arc on the surface of the material allows to receive the melted layer with a width of $40-60 \mathrm{~mm}$ in a single pass on the surface of the concrete, and the clamping of the magnetic field to the surface allows to realize high-intensity heat flows into the material $\left(107-108 \mathrm{~W} / \mathrm{m}^{2}\right)$ [3]. This design of the plasma generator also allows the processing of building products not only of limited dimensions (brick, wood [4]) but also of extended surfaces, for example, concrete wall panels.

The adhesion strength of the molten layer with the base material can serve as an indicator of the degree of destruction of the crystalline hydrates of cement stone (brittle matrix of the composite material) in the transition layer under the thermal influence.

The effect of the movement speed of the plasma generator on the treatment surface (exposure time) is shown in Fig. 1 [5]. The graph shows that the decrease in the speed leads to an increase in the degree of destruction of crystalline hydrates and, accordingly, to a decrease in the adhesive strength of the covering. However, for all compositions with processing speeds of more than $5 \mathrm{~cm} / \mathrm{sec}$ adhesive strength corresponds to GOST № 11024.84 (at least $1 \mathrm{mPa}$ ).

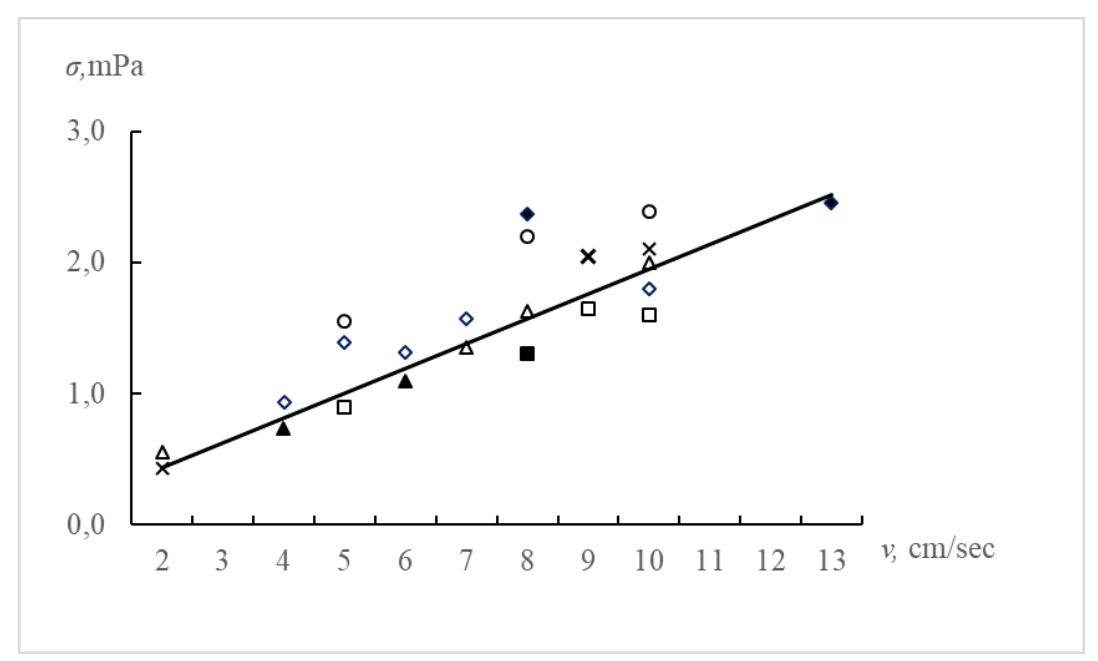

Fig. 1. Influence of speed of processing of concrete on the adhesive durability of a covering.

Here and further: $\Delta$ - granite sand; $\diamond$ - shredded glass; $\odot-$ shamotny sand; $\square-$ expanded clay and perlite sand; $\times$ - fireclay and expanded clay sand, blackened points correspond to a 2 -fold fusion

The thickness of the molten layer can be estimated knowing the characteristics of the thermal effect of the plasma generator on the surface and the speed of its movement (exposure time):

$$
\xi=R \frac{Q a_{1} \tau_{0}}{\lambda_{1} T_{n} \eta}, R=\sqrt{\frac{a_{2}}{a_{1}}} \frac{\lambda_{1}}{\lambda_{2}}
$$


where: $Q$ - specific heat flow rate; $\xi$ - is the maximum depth of melting; $\tau_{0}$-the time of exposure of the plasma to the material; $\lambda_{2}, a_{2}$ - coefficients of thermal conductivity and thermal diffusivity of the material; $a_{1}, \lambda_{1}$ - coefficients of thermal diffusivity and thermal conductivity of the melt; $T_{n}$ - temperature of melting of the material; $R$ - the dimensionless parameter characterizing the ratio of the thermal characteristics of the melt material; $\eta=$ 0,63 - dimensionless parameter.

Theoretical results are in agreement with experimental data (Fig. 2) obtained by means of the micrographs of the concrete surface layer by the adhesive method with fillers shown in Fig. 1. The volume ratio of cement / dispersed phase is $1 / 3$. It should be noted that a special textured layer based on white cement with the above aggregates (granite sand, crushed glass, fireclay sand, expanded clay and perlite sand and fireclay and expanded clay sand) was used to obtain protective and decorative coverings on concrete by the melting method.

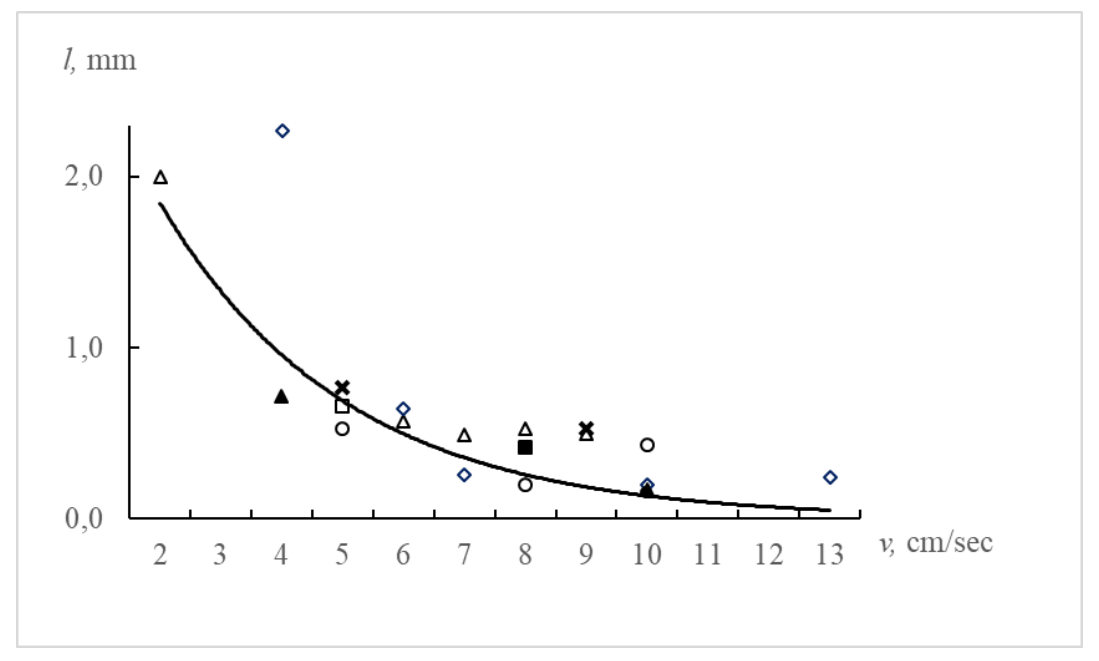

Fig. 2. Influence of speed of processing on thickness of the melted-off layer

Data on the melt temperature, the melt front velocity, the temperature of the material needed to calculate the processes occurring in the surface layer during plasma treatment of concrete is given in the monograph [6] and implemented using the program [7].

\section{Performance characteristics of protective and decorative coverings}

The quality of the obtained protective and decorative covering, which determines its performance, is estimated by durability and vapour permeability, with simulated behaviour of building structures with a protective and decorative layer under the influence of natural factors. The durability of coverings was investigated in the climatic chamber according to the method [8].

The effect of "conditional years" of operation on water permeability (waterproofing properties) is shown in Fig. 3. The increase in the service life of the covering leads to a decrease in waterproofing properties (about 1,5 times) for 30 "conditional years" of work for all types of filler. The presence of pores into the molten layer facilitates the migration of moisture through it and protects against peeling at an ambient temperature below $0^{\circ} \mathrm{C}$ (moisture freezing). 


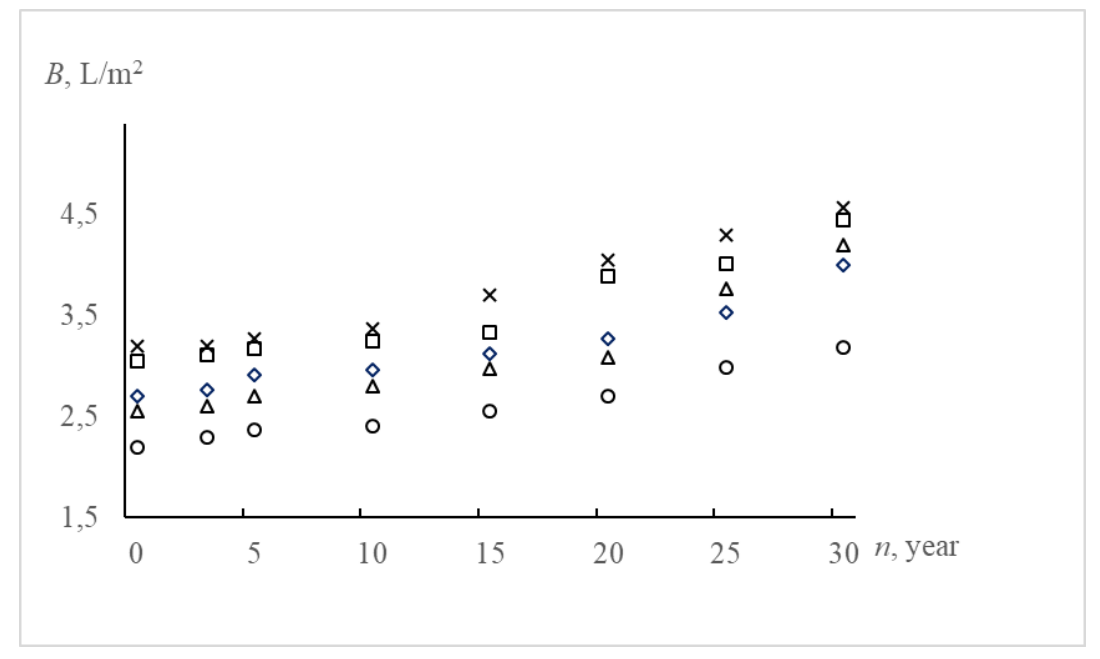

Fig. 3. Water permeability of coverings depending on operation term

The effect of alternating freezing-thawing cycles on the adhesive strength of the covering is shown in Fig. 4. The graph shows that increase in the number of cycles of frost resistance for almost all types of aggregates increases, which is associated with the hardening of the matrix (cement stone) due to the restoration of destroyed at high temperature crystal hydrates of cement stone. The highest value of adhesive strength corresponds to the filler based on fireclay sand with the increase of the adhesive strength by $5 \%$. Frost resistance of plasma coverings corresponds to GOST 10060.87.

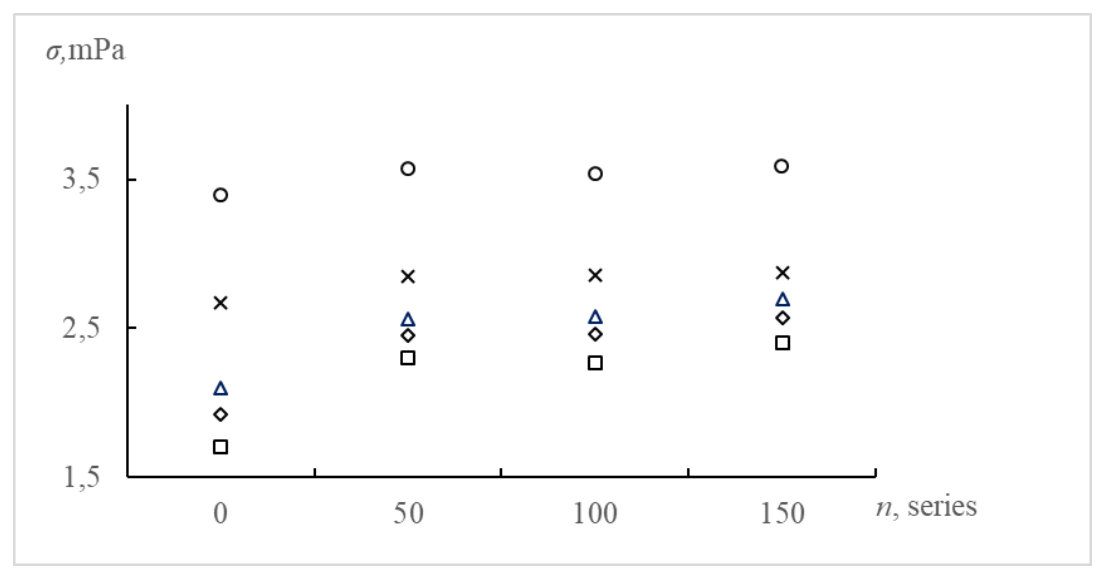

Fig. 4. Adhesive durability of coverings depending on number of cycles of alternate freezing-thawing.

The influence on "conditional years" of operation on optical characteristics (K, \% diffuse reflection coefficient, $\beta, \%-$ darkening degree) is given in Table 1 . The maximum reduction in the degree of darkening is $\sim 30 \%$ for 30 "conditional years" of operation.

Table 1. Influence of "conditional years" of operation on optical characteristics of the covering

\begin{tabular}{|c|c|c|c|c|c|c|}
\hline Through "n" of & & \multicolumn{5}{|c|}{ Code of structure } \\
\cline { 3 - 7 } $\begin{array}{c}\text { conditional } \\
\text { years of } \\
\text { operation }\end{array}$ & $\begin{array}{c}\text { Color } \\
\text { Indicators }\end{array}$ & $\mathbf{1}$ & $\mathbf{2}$ & $\mathbf{3}$ & $\mathbf{4}$ & $\mathbf{5}$ \\
\hline $\begin{array}{c}\text { prior to } \\
\text { researches }\end{array}$ & $\mathrm{K}$ & 59,2 & 45,8 & 28,5 & 18,0 & 32,8 \\
\cline { 2 - 7 } & $\beta$ & - & - & - & - & - \\
\hline
\end{tabular}




\begin{tabular}{|c|c|c|c|c|c|c|}
\hline \multirow{2}{*}{3} & $\mathrm{~K}$ & 58,5 & 45,0 & 28,0 & 17,8 & 32,1 \\
\cline { 2 - 7 } & $\beta$ & 1,2 & 1,7 & 1,8 & 1,1 & 2,1 \\
\hline \multirow{2}{*}{5} & $\mathrm{~K}$ & 57,3 & 44,6 & 27,3 & 17,1 & 31,5 \\
\cline { 2 - 7 } & $\beta$ & 3,2 & 2,6 & 3,6 & 5,0 & 3,9 \\
\hline \multirow{2}{*}{10} & $\mathrm{~K}$ & 55,4 & 40,2 & 25,8 & 16,4 & 29,5 \\
\cline { 2 - 7 } & $\beta$ & 6,4 & 12,2 & 9,5 & 8,9 & 10,1 \\
\hline \multirow{2}{*}{15} & $\mathrm{~K}$ & 51,8 & 38,3 & 24,0 & 15,0 & 27,5 \\
\cline { 2 - 7 } & $\beta$ & 12,5 & 18,2 & 15,8 & 16,7 & 16,2 \\
\hline \multirow{2}{*}{20} & $\mathrm{~K}$ & 49,4 & 34,5 & 20,3 & 14,2 & 24,2 \\
\cline { 2 - 7 } & $\beta$ & 16,6 & 24,7 & 28,8 & 21,1 & 26,2 \\
\hline \multirow{2}{*}{25} & $\mathrm{~K}$ & 48,5 & 33,5 & 20,0 & 13,1 & 23,1 \\
\cline { 2 - 7 } & $\beta$ & 18,1 & 26,8 & 29,8 & 24,5 & 29,5 \\
\hline \multirow{2}{*}{30} & $\mathrm{~K}$ & 47,0 & 32,0 & 19,0 & 12,6 & 23,0 \\
\cline { 2 - 7 } & $\beta$ & 20,6 & 30,1 & 33,4 & 30,0 & 30,0 \\
\hline
\end{tabular}

\section{Architectural properties of protective and decorative coverings}

Plasma technology has a wide range of possibilities for producing molten layers on concrete with different architectural expressiveness, which is realized by using different fillers of the textured layer, inorganic dyes (salts of different metals) introduced into this layer (Fig. 5) and by moving the plasma generator with different trajectories on the surface of the treatment (Fig. 6).

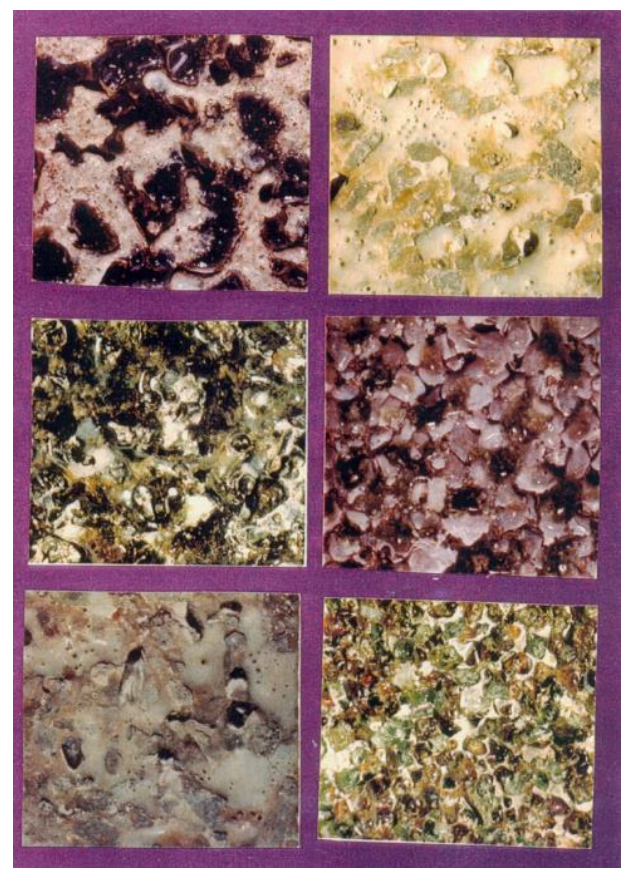

Fig. 5. Samples of the plasma melted-off coverings on concrete 


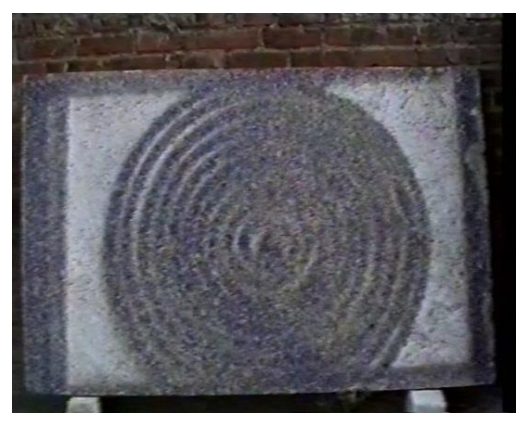

Fig.6. The panel with the plasma melted-off protective and decorative covering

\section{Practical implementation of the technology}

The practical implementation of this technology was carried out at the enterprises of the construction industry in the form of an automated complex for processing concrete wall panels (Fig.7), the technical characteristics of which are given in Table 2.

Table 2. Technical characteristics of the plasma installation

\begin{tabular}{|c|c|c|}
\hline Power consumption & $\mathrm{kW}$ & 140 \\
\hline Performance & $\mathrm{m}^{2} / \mathrm{h}$ & $20 \ldots 30$ \\
\hline Gaseous nitrogen & $\mathrm{Nm}^{3} / \mathrm{h}$ & 1,0 \\
\hline Water for cooling & $\mathrm{m}^{3} / \mathrm{h}$ & 2,0 \\
\hline The energy cost of obtaining coverage & $\mathrm{kWh} / \mathrm{m}^{2}$ & $3 \ldots 5$ \\
\hline Operating mode & & automatic \\
\hline Service staff & pers. & 2 \\
\hline
\end{tabular}

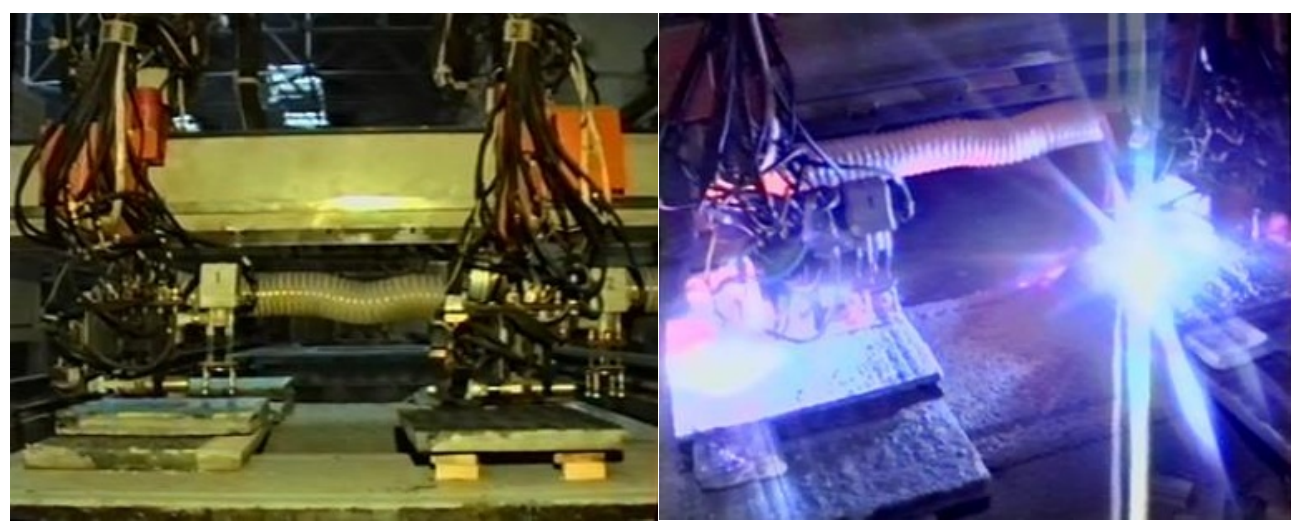

Fig. 7. Installation for protective and decorative coverings on wall panels based on plasma cutting machine "Comet".

\section{Conclusion}

The results obtained by means of the development plasma technology and equipment based on the plasma generator with the electric arc controlled by magnetic fields were applied in 
the construction industry and also may be used for the creation of special coverings on materials such used in other industries (metallurgical, chemical, nuclear, etc.).

\section{References}

1. G. M. Zaitseva, On the Construction Sites of Russia, 7, 42-46 (1984)

2. A. M. Lykov, V. A. Samsonov, N. N. Naumenko, V. D. Shimanovich, XI All-Union Conference "Theory and Practice of Thermal Covering", 2, 28-32 (1988)

3. V. A. Samsonov, A. M. Lykov, N. N. Naumenko, Heat and Mass Transfer - MMF. Section II, 88-90 (1988)

4. G. G. Volokitin, N. K. Skripnikova, O. G. Volokitin, V. V. Shehovitov, A. G. Luchkin, N. F Kashapov, VII Conference on Low Temperature Plasma in the Processes of Functional Covering Preparation (2016)

5. A. M. Lykov, N. N. Naumenko, $14^{\text {th }}$ International Symposium on Plasma Chemistry, 4, 2069-2074 (1999)

6. A. M. Lykov, N. N. Naumenko, Plasma modification of the material surface (Ark, Minsk, 2012)

7. A. M. Lykov, The Program for the Calculation of Thermal Processes of Modification of the Surface of Materials. Certificate of State Registration of Computer Programs. № 2018617509 from 25.06.2018

8. The Method of Complex Testing of the Finishing Covering for Durability. Scientific Research Institute (MPSM BSSR, Minsk, 1978) 